06

\title{
Электронная микроскопия и элементный состав приповерхностного слоя кристаллов LiF, облученных электронами
}

\author{
() М.А. Муссаева ${ }^{1}$, Э.М. Ибрагимова ${ }^{1,2, q}$ \\ ${ }^{1}$ Институт ядерной фризики АН Республики Узбекистан, Улугбек, Ташкент, Узбекистан \\ ${ }^{2}$ Центр передовых технологий при Министерстве инновационного развития Республики Узбекистан, Ташкент, Узбекистан \\ ฯ E-mail: ibragimova@inp.uz
}

Поступило в Редакцию 12 ноября 2018 г.

В окончательной редакции 21 ноября 2018 г.

Принято к публикации 21 ноября 2018 г.

\begin{abstract}
Методами электронной микроскопии и колебательных спектров исследованы наночастицы Li, сформированные на сколотой поверхности кристаллов $\mathrm{LiF}$ при облучении пучком электронов с энергией $4 \mathrm{MeV}$ дозой $5 \cdot 10^{16} \mathrm{~cm}^{-2}$. Предполагается, что при интенсивном облучении в результате ионизации происходит радиолиз и удаление фтора по межблочным границам, где оставшиеся катионы лития нейтрализуются электронами и образуют наночастицы $\mathrm{Li}$, которые собираются и взаимно ориентируются в микронити. Такая функциональная поверхность представляет практический интерес.
\end{abstract}

DOI: 10.21883/PJTF.2019.04.47335.17583

Кристаллы $\mathrm{LiF}$ с кубической симметрией имеют самую плотную кубическую упаковку анионов фтора, самую большую из всех материалов ширину запрещенной зоны, низкую гигроскопичность, тканеэквивалентную плотность, поэтому они широко применяются в дозиметрии ядерных излучений. Формирование микро- и нанонитей металлов на диэлектрике разными способами является актуальной задачей для функциональных материалов энергетики. Высокая скорость выделения энергии быстрых ионов с $E \geqslant 1 \mathrm{MeV} \cdot \mathbf{u}^{-1}$ в электронную подсистему приводит к генерации ударных волн и разрушению материалов, интенсивному неупругому распылению материалов, локальному плавлению, аморфизации, формированию треков и созданию необычных фаз [1]. Повреждения кристаллической решетки LiF из-за воздействия электрического разряда изучались с помощью рентгеновской топографии, оптической и электронной микроскопии. Обнаружены $V$-образные расколы шириной $0.01-0.2 \mu \mathrm{m}$ и глубиной $10-100 \mu \mathrm{m}$ в плоскостях $\{100\}$, где прошли искровые разряды [2]. Недавно было показано формирование тонкого люминесцирующего слоя с оптическими центрами $F_{2}^{-}$и $F_{3}^{+}$в кристаллах $\mathrm{LiF}$ под действием излучения тлеющего разряда $[3,4]$. Облучение $\mathrm{LiF}$ тяжелыми ионами $(\mathrm{Au}, \mathrm{Pb}, \mathrm{Se}, \mathrm{Xe})$ до доз $>10^{8} \mathrm{R}$ при температурах $\geqslant 100-200^{\circ} \mathrm{C}$ создает агрегаты 2-3 точечных дефектов в катионной и анионной подрешетках, а при дозах $>10^{9} \mathrm{R}$ уже формируются коллоиды $\mathrm{Li}$ и молекулярные кластеры $\left(n \mathrm{~F}_{2}\right)$, которые наблюдаются в сканирующем электронном микроскопе после травления треков ионов [5]. Коллоиды Li дают более широкий ESR-сигнал из-за наноразмеров и не отжигаются до расплавления $\mathrm{LiF}$ при $870^{\circ} \mathrm{C}$. При измерениях методом ядерного магнитного резонанса ядер ${ }^{7} \mathrm{Li}$ в облученном нейтронами LiF было обнаружено несимметричное расщепление смещенного Knight-сигнала, узкая компонента которого была приписана частицам метал- лического Li [6]. С помощью сканирующего электронного и атомно-силового микроскопов наблюдались треки, бугорки, наноструктуры, возникающие на поверхности кристаллов $\mathrm{LiF}$ при облучении ионами $\mathrm{N}(18 \mathrm{MeV})$, $\mathrm{Kr}(117 \mathrm{MeV})$, Хе $(195 \mathrm{MeV})$ флюенсами $\sim 10^{11} \mathrm{~cm}^{-2}$ и сильноточными (60-300 A/ $\left.\mathrm{cm}^{2}\right)$ электронными импульсами (2 ns) флюенсами (5-7) $10^{13} \mathrm{~cm}^{-2}$ [7]. Выпуклости размером от 10 до $30 \mathrm{~nm}$, хаотично расположенные на поверхности кристаллов $\mathrm{LiF}$ после высокодозного $\left(5 \cdot 10^{8} \mathrm{R}\right)$ гамма-облучения и последующего отжига при 600-650 K, были обнаружены с помощью атомносилового микроскопа и приписаны наночастицам Li [8]. Методами нано- и микроиндентирования, химического травления, оптической и атомно-силовой микроскопии было обнаружено формирование тонких слоев с высокой нанотвердостью на поверхности кристаллов LiF, облученных бета-частицами (энергия электронов $75 \mathrm{keV}$, флюенс $\left.\sim 4.3 \cdot 10^{18} \mathrm{~m}^{-2}\right)[9,10]$.

Анализ литературы выявил мало данных по облучению $\mathrm{LiF}$ электронами с энергией больше $1 \mathrm{MeV}$, которые не только представляют научный интерес, но и имеют большой практический потенциал для разработки эффективной радиационной технологии.

Цель данного эксперимента - исследовать формирование наночастиц металлического $\mathrm{Li}$ на сколотой поверхности кристалла LiF при высокодозном интенсивном облучении ускоренными электронами.

Объектами служили оптические полированные беспримесные кристаллы $\mathrm{LiF}$ толщиной 1-2 mm. Облучение проводилось в воздушной среде на ускорителе электронов „Электроника У-003“ при следующих условиях: средняя энергия электронов $4 \mathrm{MeV}$, импульсы тока $4.5 \cdot 10^{-6} \mathrm{~s}$, плотность тока пучка от 0.1 до $1 \mu \mathrm{A} / \mathrm{cm}^{2}$, интегральные флюенсы набирали от $10^{15}$ до $5 \cdot 10^{16} \mathrm{~cm}^{-2}$. Спектры колебаний связи $\mathrm{Li}-\mathrm{F}$ измерялись на инфракрасном (ИК) фурье-спектрометре в режимах пропус- 


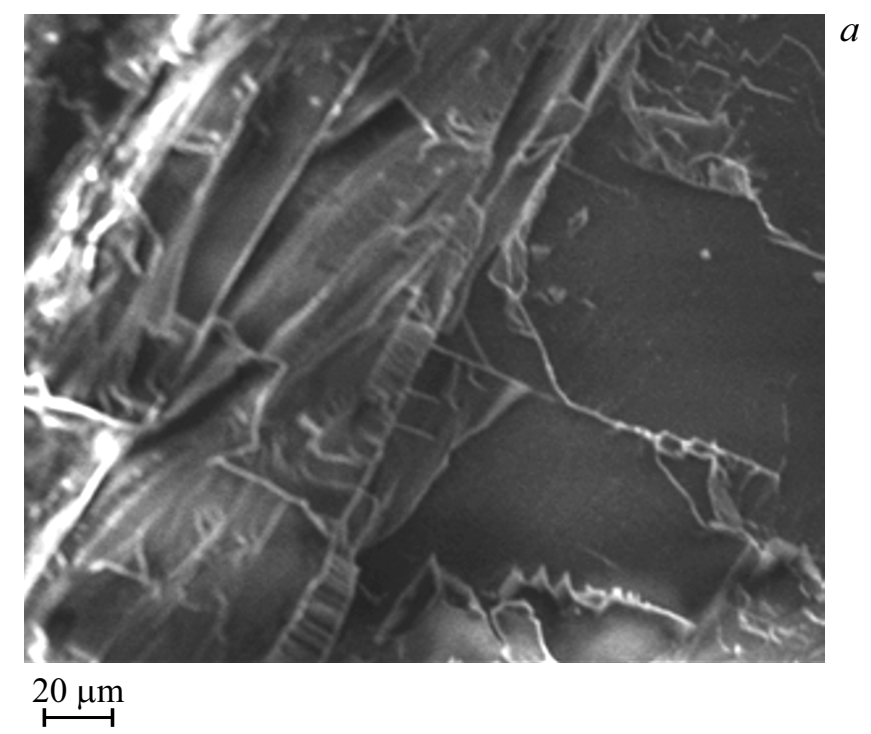

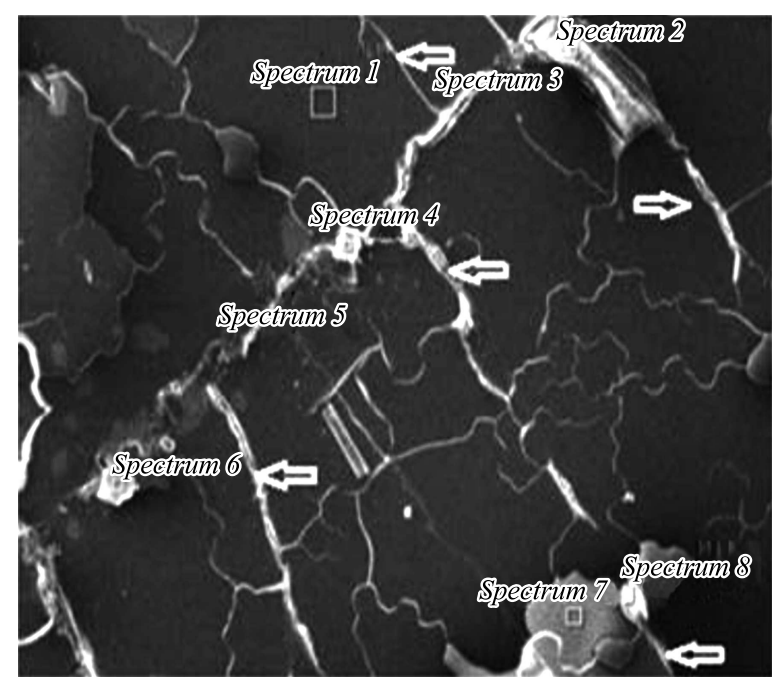

$100 \mu \mathrm{m}$

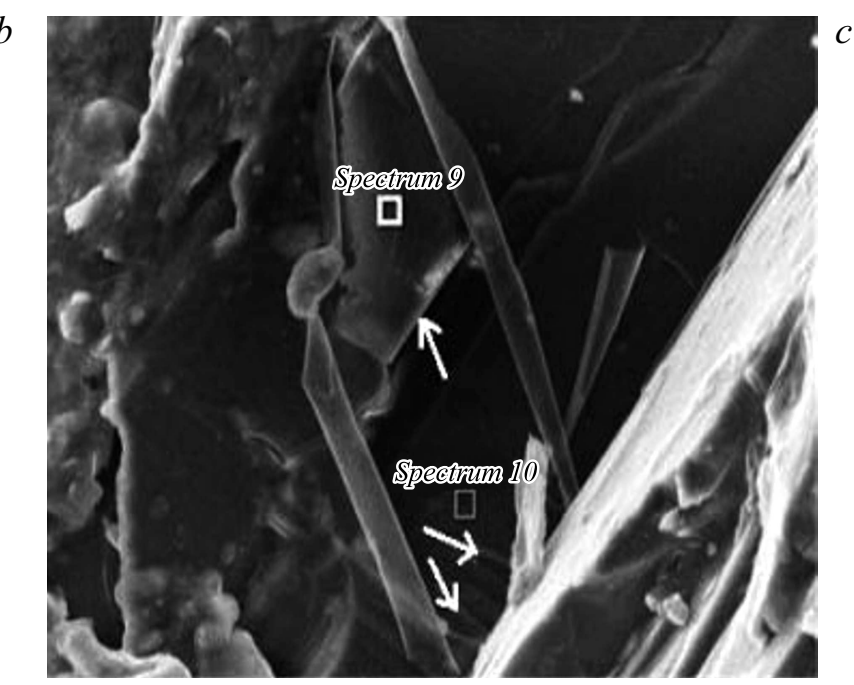

$25 \mu \mathrm{m}$

Рис. 1. Снимок поверхности (100) скола кристалла LiF: необлученного (a), облученного $4 \mathrm{MeV}$ электронами флюенсом $10^{15} \mathrm{~cm}^{-2}$ при токе $1 \mu \mathrm{A}$ при разных увеличениях $(b, c)$.

кания и ослабления внутреннего отражения для приповерхностного слоя до $20 \mu \mathrm{m}$, что позволило бы увидеть снижение амплитуды полосы связи $\mathrm{Li}-\mathrm{F}$ из-за потери фтора.

Перед наблюдениями в электронном микроскопе на сколотую поверхность (100) диэлектрических кристаллов LiF наносился слой графита толщиной $30 \mathrm{~nm}$ методом магнетронного напыления в вакууме для удаления заряда, накапливающегося в диэлектрике под пучком электронов $100 \mathrm{keV}$. Микрофотографии образцов до и после облучения на ускорителе получались на сканирующем электронном микроскопе EVOMA10 (Zeiss) при разных увеличениях с помощью детектора вторичных электронов, а локальный элементный состав определялся с помощью встроенной приставки EDS c детектором SDD (Oxford Instr.) в интервале энергий квантов рентгеновского излучения от 0.1 до $30 \mathrm{keV}$.

На поверхности скола необлученного кристалла $\mathrm{LiF}$ (рис. $1, a$ ) видны ступеньки, повышенная яркость которых обусловлена эмиссией электронов с металла на ребре. Локальный элементный анализ обнаружил на необлученной поверхности $100 \%$ фтора, так как литий не определяется EDS, а других элементов не было обнаружено, поэтому нарушение стехиометрии приповерхностного слоя оценить не удалось. Авторы наблюдали в тлеющем разряде рекомбинационную люминесценцию центров $F_{2}^{-}$и $F_{3}^{+}[3,4]$. Это возможно при удалении фтора, так как междоузельный фтор нестабилен и не наблюдается в спектрах после облучения. На рис. $1, b, c$ показаны десять мест определения локального элементного состава поверхности после облучения дозой $10^{15} \mathrm{~cm}^{-2}$ при 

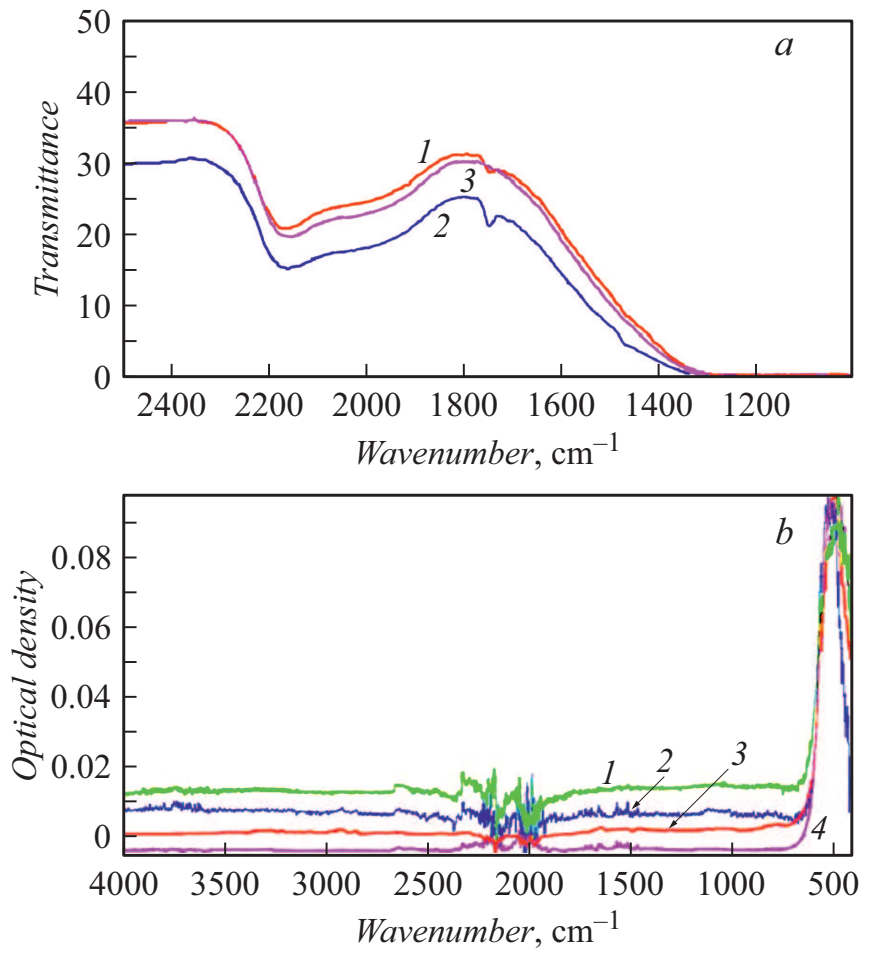

Pис. 2. Спектры ИК-поглощения кристаллов $\mathrm{LiF}$ после облучений электронами с энергией $4 \mathrm{MeV}$. $a-$ в режиме пропускания с разных сторон: 1 - необлученная боковая сторона, 2 - экспонированная при токе $0.1 \mu \mathrm{A}$ до дозы $10^{15} \mathrm{~cm}^{-2}, 3-$ тыльная; $b-$ в режиме отражения: $1-$ экспонированная при токе $0.4 \mu \mathrm{A}$ до дозы $5 \cdot 10^{16} \mathrm{~cm}^{-2}, 2$ - тыльная, 3 - после релаксации в течение одного дня, $4-$ после отжига до $400^{\circ} \mathrm{C}$.

токе $1 \mu$ А. Как на гладких участках поверхности, так и в местах разрыва нанесенной С-пленки по межблочным границам видны яркие параллельные нити из металлических частиц (лития), эмитирующие электроны, на темном фоне диэлектрика. Анализ показал, что в точках 1, 7-10 спектры содержат только $100 \%$ F (поскольку $\mathrm{Li}$ не определяется детектором даже в месте его концентрирования, а других металлов не обнаружено), а в точках 2 и 3 появляется примесь 1-2 mass\% O. Поскольку фтор имеет более высокую электроотрицательность (3.98), чем кислород (3.44), и меньший ионный радиус $(73 \mathrm{pm})$, чем кислород (132 pm), последний не может вытеснить фтор, а может занять только вакансию фтора на поверхности. Обнаружение в точках 2 и 3 кислорода может служить доказательством локального удаления фтора в результате радиолиза и эмиссии фтора. В точках 4-6 оказалась пленка проводящего клея для крепления образца на столике в камере микроскопа и снятия заряда с диэлектрика. Светлые пятна размерами $1-20 \mu \mathrm{m}$, где имела место локальная эмиссия фтора из дефектного канала между монокристаллическими блоками, соответствуют областям, в которых сформировались нанопластинки лития, как это наблюдалось при облучении гамма-квантами и электронами $[11,12]$.
ИК-спектроскопия в режимах пропускания и отражения была использована для обнаружения ослабления полосы связи $\mathrm{Li}-\mathrm{F}$ в результате эмиссии фтора с облученной поверхности. На рис. 2 показаны ИК-спектры, измеренные в режимах пропускания и отражения после облучений электронами с энергией $4 \mathrm{MeV}$ при различных токах и дозах, а также после отжига до $400^{\circ} \mathrm{C}$ для сравнения с образованием агрегатов 2-3 точечных дефектов в катионной и анионной подрешетках и коллоидов Li [5-7]. В спектре ИК-пропускания после облучения электронами при токе $100 \mathrm{nA}$ дозой $10^{15} \mathrm{~cm}^{-2}$ (рис. 2, a) наблюдались полосы поглощения 2170, 2000 и $1750 \mathrm{~cm}^{-1}$ наноколлоидов $\mathrm{Li}$, но не видны колебания связи $\mathrm{Li}-\mathrm{F}$ в областях $900-750$ и $650-400 \mathrm{~cm}^{-1}$. В спектрах отражения (рис. $2, b$ ) после интенсивного облучения при токе $400 \mathrm{nA}$ полосы $900-750 \mathrm{~cm}^{-1}$ совсем не видно, полоса $650-400 \mathrm{~cm}^{-1}$ очень ослаблена и во всем ИК-диапазоне имеет место рассеяние, характерное для свободных электронов в металле. Из-за радиолиза (вылета фтора) при температуре облучения выше $100^{\circ} \mathrm{C}$ и плотности тока пучка электронов $1 \mu \mathrm{A} / \mathrm{cm}^{2}$ число связей $\mathrm{Li}-\mathrm{F}$ в приповерхностном слое $20 \mu \mathrm{m}$ резко уменьшается, соответственно обе полосы $\mathrm{Li}-\mathrm{F}$ резко ослабляются, полоса $450 \mathrm{~cm}^{-1}$ от колебаний молекул $\mathrm{F}_{2}$ (междоузельные ионы фтора) тоже ослабляется. Тогда остается полоса $500-550 \mathrm{~cm}^{-1}$ от колебаний связей $\mathrm{Li}-\mathrm{Li}$ в агрегатах, что согласуется с динамикой решетки и функцией плотности состояний $\mathrm{LiF}$ [13]. Это объясняет и подтверждает появление чешуек и нитей $\mathrm{Li}$ на микроснимках облученной поверхности и высокую нанотвердость сформированных тонких слоев на поверхности кристаллов $\mathrm{LiF}$, облученных бета-частицами $[9,10]$. Термический отжиг до $400^{\circ} \mathrm{C}$ полностью устраняет рассеяние на носителях и усиливает полосу $500 \mathrm{~cm}^{-1}$ в соответствии с ростом количества агрегатов $\mathrm{Li}_{2}[4,5,7]$.

Ионизирующее облучение диэлектрика создает поверхностный электрический потенциал, в результате резко возрастает поверхностная электропроводность [14].

Показана эффективность сочетания методов электронной микроскопии и колебательных спектров металлических наночастиц в приповерхностном слое диэлектрической матрицы. На поверхности скола кристалла LiF, облученного высокими дозами электронов с энергией $4 \mathrm{MeV}$, обнаружены наночастицы $\mathrm{Li}$, которые после радиолиза и удаления фтора собираются и взаимно ориентируются в микронити (это согласуется с обнаруженным нами ранее возрастанием электропроводности), что имеет потенциал применения в качестве нанои микроструктурированных электродов на диэлектрике в современных литиевых аккумуляторах или других устройствах.

Работа поддержана грантом ОТ-Ф2-26 Министерства инновационного развития Республики Узбекистан и Центром передовых технологий Министерства инновацион- 
ного развития Республики Узбекистан, предоставившим аналитические приборы.

\section{Список литературы}

[1] Комаров Ф.Ф. // УФН. 2003. Т. 173. № 12. С. 1287-1318. DOI: $10.3367 /$ UFNr.0173.200312b.1287

[2] Akashi Y., Yoneda Y. // J. Appl. Phys. 1972. V. 11. N 8. P. 1090-1096.

[3] Милютина У.В., Петровский А.Ф., Ракевич А.Л., Мартынович Е.Ф. // Письма в ЖТФ. 2014. Т. 40. В. 9. С. 64-71.

[4] Тютрин А.А., Глазунов Д.С., Ракевич А.Л., Мартынович Е.Ф. // Письма в ЖТФ. 2018. Т. 44. В. 15. С. 12-19. DOI: 10.21883/PJTF.2019.04.47335.17583

[5] Schwartz K.H. // RAU Sci. Rep. Comput. Model. New Technol. 1998. V. 2. P. 5-14.

[6] Beuneu F., Vajda P., Zogal O.J. // Nucl. Instrum. Meth. Phys. Res. B. 2002. V. 191. N 1-4. P. 149-153. https://doi.org/10.1016/S0168-583X(02)00535-9

[7] Здоровеи М., Акилбеков А., Русакова А., Даулетбекова А., Абуова Ф., Мухышбаева А. // Изв. вузов. Физика. 2009. № 8/2. C. 331-333.

[8] Брюквина Л.И., Мартынович Е.Ф. // ФТТ. 2012. Т. 54. B. 12. C. 2056-2061.

[9] Федоров В.А., Новиков Г.В. // Вестн. Тамбов. ун-та. 2013. T. 18. № 4. C. 1784-1785.

[10] Федоров В.А., Новиков Г.В., Новгородов Л.А., Васильева С.В., Подкауро А.М. // Вестн. Тамбов. ун-та. 2014. Т. 19. № 2. C. 717-721.

[11] Муссаева М.А., Ибрагимова Э.М., Бузриков Ш.Н. // Оптика и спектроскопия. 2018. Т. 124. В. 5. С. 612-616. DOI: 10.21883/OS.2018.05.45940.293-17-17

[12] Зефирова В.Л., Колонцова Е.В., Луценко В.П. // Вестн. МГУ. Сер. 3. Физика, астрономия. 1976. Т. 17. № 5. С. 631633.

[13] Dolling G., Smith H.G., Nicklow R.M., Vijayaraghavan P.R., Wilkinson M.K. // Phys. Rev. 1968. V. 168. P. 970-979. DOI: https://doi.org/10.1103/PhysRev.168.970

[14] Костюков Н.С., Маслов В.В., Муминов М.И. Радиационная стойкость диэлектриков. Ташкент: Фан, 1981. 213 с. 